\title{
A taxonomic revision of the genus Brachystelma R.Br. in India
}

\author{
Prasad K. \& P. Venu, 2020
}

Published by Bishen Singh Mahendra Pal Singh, Dehra Dun. Hardbound.

ISBN: 978-81-946147-7-7. Pages: 114; illustrations 21; 37 photo plates; 9 distribution maps. Price: ₹1,750/-

The plant groups that consist of short-lived ephemerals or geophytes with underground storage organs such as bulbs, corms, tubers or rhizomes are inadequately explored and studied due to their narrow seasonality and highly restricted distribution ranges. Such plant groups are poorly represented in many of the earlier Floras and in herbaria. In this case, besides the paucity of voucher specimens in herbaria, the available specimens are of little useful as they are devoid of significant floral features (usually lost while processing), and the protologues are also with imperfect description and type details. As a consequence, many of the later Floras tend to repeat only the existing information besides reporting the sporadically described novelties and updated distribution ranges. Hence, revision of such plant groups is of the utmost importance.

Brachystelma R.Br. (Apocynaceae: Asclepioideae) is one of the poorly studied and little-known genera of geophytic plants in India. As mentioned by the authors in the book, this genus has been studied by very few institutions such as the Shivaji University, Kolhapur, the Sri Krishnadevaraya University, Ananthapuramu, and the Rapinat Herbarium, Tiruchirappalli. The genus is known for its restricted distribution in arid and semi-arid zones of the country.

The revision deals with 38 taxa $[34$ species (including five new species and one new combination) and four varieties], supplemented with 21 illustrations, 37 colour photo plates and 9 distribution maps, which would help even the nontaxonomists to identify the species of Brachystelma very easily. The phenotypic variations observed among the species are well-explained under the general morphology of the genus and also supplemented with photo plates (Plates 1-3). The species have been divided into four different groups based on the nature of habit and the type of corolla and are enumerated based on morphological affinities rather than in alphabetical order.

A much appreciable aspect of this revision is that most of the descriptions are original and relatively comprehensive, and prepared based on freshly collected specimens as opposed to many other revisions that are published based majorly on herbarium specimens.

The colour photo plates clearly depict the diagnostic morphological features of these plants, and the maps

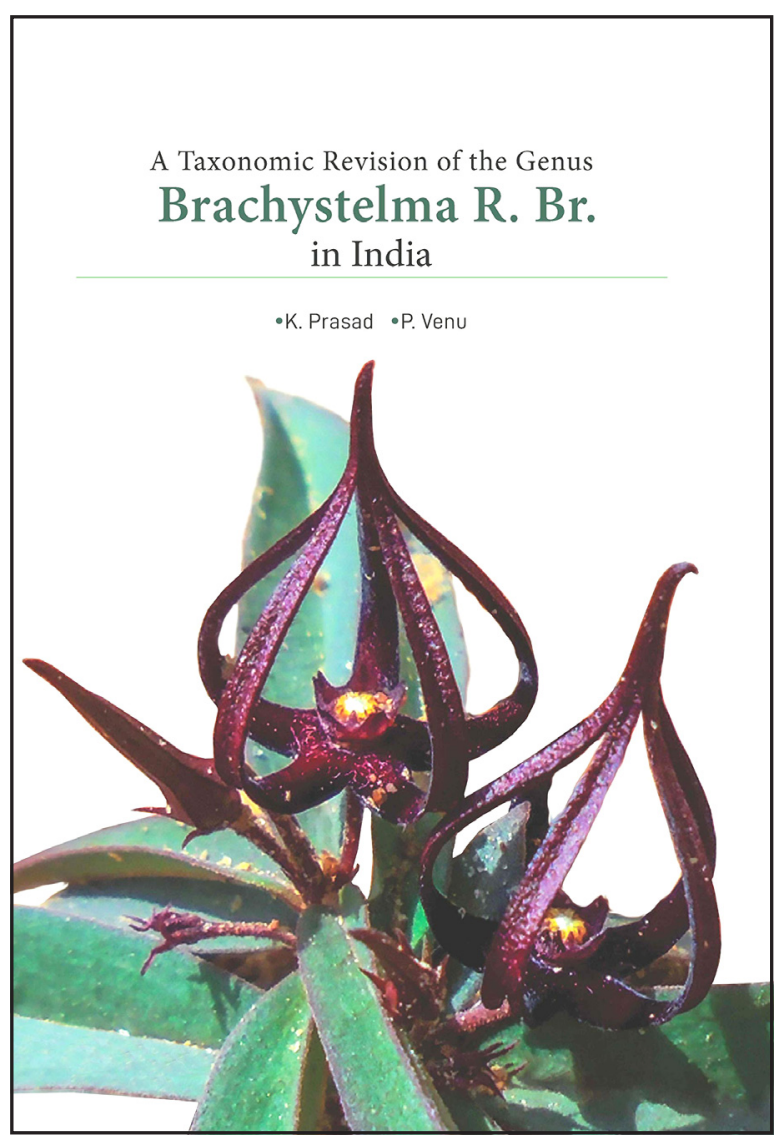


are helpful in understanding the distribution pattern of the different Brachystelma species in India. Etymology of specific/varietal epithets is provided for all accepted names. For every taxon, phenology, habitat, distribution details and specimens examined are provided.

A feature that adds value to the revision is the 'notes' that provides additional information, either nomenclatural or taxonomical. Such notes provide an idea on the clear understanding of the authors of all the species of the genus in India. The authors' critical understanding of the genus can be evidenced from justifying the distinct status of the genus instead of merely following the recent revisions based on molecular studies on South African species of Caralluma, Ceropegia, and Brachystelma.

This revision on Brachystelma assumes importance in the light of their edible tubers, aesthetic value and threat status of the species. The habitats of this genus are very often treated as wastelands and hence are prone to anthropogenic influence for developmental activities. Most of the species have been categorised under various IUCN threat categories and five of them are even considered as 'presumably extinct', a fact that demonstrates the vulnerability of this genus. This emphasizes the need for creating conservation zones for these arid zone species. The book is well produced with good text design and layout, and the authors Prasad and Venu, are to be congratulated for bringing this noteworthy publication. The book is highly recommended for those interested in the plants, vegetation and ecology of arid zones as well as for policy makers and conservationists.

D. Narasimhan, Chennai - 600059 